\title{
The Impact of Project Cost Management on Project Performance
}

\author{
Jun Ouyang \\ School of Management Engineering, Zhengzhou University; Henan Medical Design Institute Co., \\ Ltd, Zhengzhou, China \\ 864687446@qq.com
}

Keywords: cost and performance management, impact relationship, problem analysis, improvement suggestions.

Abstract: The project cost management level reflects the core competitiveness of the company to a certain extent. At this stage, the project is becoming more and more complex, and the cost measurement and control is more difficult. Cost management has always been an important part of the smooth implementation of the project development strategy and has a significant impact on the performance of the project. In order to explore the impact of project cost management on project performance, this paper analyzes the status of project cost management by various research methods, points out the problems existing in current project cost management, and puts forward relevant suggestions for improvement of project cost management based on the research conclusions.

\section{Introduction}

\subsection{Research Background}

At this stage, the project is becoming more and more complex, and the cost measurement and control is more difficult. Cost management has always been an important part of the smooth implementation of the project development strategy and has a significant impact on the performance of the project.

\subsection{Research Significance}

This paper sorts out the relevant theories of cost management and project performance, explores the relationship between cost management and project performance through questionnaire research and empirical research, and studies the degree and size of the impact of each component of cost management on project performance. The goal of project performance is to rationally coordinate the various components of cost management, plan to enhance the competitiveness of the project, create the best project performance, and achieve sustainable and healthy development of the project.

\subsection{The Main Research Methods of This Paper}

This paper intends to adopt a literature survey method. 2 questionnaire survey method. 3 
statistical analysis method. Organize the data obtained in various ways, put them in the same table, and use statistical analysis tools to analyze the results of data aggregation to ensure the validity and credibility of the questionnaire results, and to verify the data by factor analysis. The effectiveness of the analysis, using correlation analysis and regression analysis to derive the main factors affecting business performance.

\section{Relevant research status and theoretical basis}

\subsection{Relevant Research Status}

The current theoretical research on project cost management includes: Wenwu Ma (2013) Enterprise Cost Management Research;Wenlong Liu ,Shiyou Hui , Xixue Xue (2014) Research on the impact of asset-liability ratio and financial cost on performance of construction engineering enterprises; Xin Lu, Junyong Wu,Hui Huang (2014) empirical analysis of Chinese enterprises' cost management trends based on empirical analysis of literature data; Jifeng Zhang (2017) Discussion on performance management in project cost management; Wei Ge (2017) Research on the impact of cost stickiness on firm performance_-from listed companies in China Empirical evidence; Xiaoli Duan(2018) Research on cost management and performance auditing of modern enterprises focuses on the content of cost and accounting methods.Although it is realized that cost management has certain influence on the efficiency of enterprises, it is about cost management to project performance. The impact mechanism and impact path of the impact of the project on the profitability and growth of the project are very few studies (Binqing Ma, 2013).

\subsection{Relevant Theoretical Basis}

\subsubsection{Theory of Cost Management}

Cost management refers to the planning, accounting, analysis, control and assessment of costs in the course of business operations.

A general term for a series of scientific management actions. The purpose of cost management is to achieve optimal business performance at the lowest cost by organizing a series of management activities for all personnel (Jifeng Zhang, 2017).

The main contents of cost management include: 1 Cost planning: According to the internal and external environment of the enterprise, the needs of production and operation, establish the cost target and management focus, select the scientific method of cost accounting analysis, and determine the evaluation standard of cost control effect.2 Cost accounting: A general term for a series of activities such as recording, collecting, calculating and distributing the expenses incurred by an enterprise in accordance with certain standards.3 Cost control: Based on the cost accounting, a series of activities to reduce the cost of the enterprise by various methods(Xiaoli Duan,2018).4 Cost analysis: According to the results of cost accounting, combined with the internal and external environment of the enterprise and related plans, analyze the factors affecting the cost change through certain methods and methods, and find out the general term of the activities that affect the main reasons and key factors of cost changes.5 Cost assessment: It refers to the evaluation and summary of the completion of cost-related indicators according to certain criteria according to the cost target, and promotes the completion of cost control effects(Liang Liu ,2018).

\subsubsection{Relevant Theory of Enterprise Performance}

Performance comes from English performance, it is a multi-dimensional concept, there are many definitions of it. From the same point of view, this paper considers that performance is the way, 
process, and result of an organization's or individual's activities. It is the degree of excellence in accomplishing tasks under certain resources, conditions, and circumstances. It is a measure of goals, degree of achievement, and efficiency. With feedback (Wenlong Liu, Shiyou Hui, Xixue Xue, 2014).

The definition of enterprise performance evaluation is: the enterprise uses a special method and adopts a specific indicator system.

Certain procedures, through a combination of quantitative and qualitative analysis, on the business performance and the behavior of the camp to make an objective, fair and accurate comprehensive evaluation. China's "Company Achievements" issued in 2002

The evaluation indicators set out in the Operational Evaluation Rules (Revised) have made great contributions to the enterprise performance system.

\section{Empirical Research Design}

\subsection{Cost Management Dimensional Index Selection}

\subsubsection{Basis of Selection of Dimension Indicators}

The selection of indicators in this paper has the following specific points: First, based on the views of domestic experts on the cost management system. Second, based on the views of domestic experts on the selection of cost management system indicators. Third, according to the opinions of experts from the Accounting Qualification Center of the Ministry of Finance.In the book "Financial Management" prepared by the Accounting Qualification Evaluation Center of the Ministry of Finance,the cost management is divided into five parts: cost planning, cost accounting, cost control, cost analysis and cost assessment(Wenwu Ma,2013).

According to the above experts' opinions,the following dimensional indicators of cost management are proposed: leadership, cost strategy, cost accounting analysis,and cost control assessment.

\subsubsection{Dimensional Indicators}

Leadership: Leadership support is the premise for effective cost management.The leadership role in this paper mainly includes the importance, participation, responsibility and cost management of managers in project management (Yao Ge, 2017).

Cost strategy: It mainly includes the analysis of the current status of cost in cost management, and then determines the cost target based on the current analysis results, and finally develops the cost plan.

Cost accounting analysis:It mainly involves whether the cost account setting is reasonable, whether the cost accounting method is scientific, and whether the quality cost data collection is comprehensive and timely.

Cost control assessment: refers to the behavioral process of correcting the behavior of deviation from the established goals and programs in accordance with the established cost objectives and plans during the project implementation process. Cost control mainly includes cost prior control, in-process control and post-event control(Wenlong Liu , Shiyou Hui, Xixue Xue,2014).

\subsection{Project Performance Evaluation Dimensions}

\subsubsection{Basis for Selection of Project Performance Evaluation Indicators}

In this paper, the selection of project performance dimension indicators mainly draws on Rui 
Yang's measurement of enterprise performance from two aspects of profitability and growth, and combines the standards and methods of central enterprises' comprehensive performance evaluation indicators set by China's State-owned Assets Supervision and Administration Commission (Rui Yang, 2012).

\subsubsection{Project Performance Evaluation Indicators}

(1) Profitability indicator

1) Profitability status: It mainly reflects the ability of a project to obtain profits and realize capital appreciation, mainly reflected by the relationship between income and profit, and the relationship between assets and profits.

2) Asset quality status: mainly reflects the asset management level of a project, the utilization efficiency of resources and the security of assets.

3) Debt risk status: Reflects the risks faced by a project, the level of debt commitment, and the ability to repay debt. Its main measurement indicators are asset-liability ratio and interest multiplier.

(2) Growth indicators

1) Business growth status: Reflecting the status of project capital appreciation, the level of business growth and the ability to develop in the future. The main measurement indicators are turnover growth rate and capital preservation and appreciation rate.

2) Sustainability: The ability to reflect the level of project development and innovation and social contribution. With the progress and development of society, this indicator has been increasingly valued by enterprises and society.

\subsection{Design of the questionnaire and determination of the survey object}

\subsubsection{Design of the Questionnaire}

The questionnaire is divided into four parts. The first part is the relevant background of the respondents and enterprises. The second part is the project cost management measurement, which is conducted from four projects, namely leadership, cost strategy, cost accounting and analysis, cost control and assessment. The third part is the evaluation index of project performance. Starting from the two aspects of profitability and growth, profitability is measured from the company's profitability, asset debt status and debt risk status. Growth is measured by business growth and sustainability. In order to supplement the first three parts of the questionnaire to obtain more effective suggestions, the questionnaire in this paper sets up an open subjective question in the fourth part. In the design of the questionnaire, the internationally accepted five-point Linker Scale is used to evaluate the problem (1=completely non-conformity, $2=$ not consistent, $3=$ unsure, 4=comparative, $5=$ very meets the).

\subsubsection{Determination of the Survey Object}

In order to ensure the reliability and credibility of the questionnaire survey, the survey subjects are mainly selected to develop more mature industries such as engineering construction industry. Because of their relatively perfect development, the cost management is relatively mature; in order to improve the validity of the survey data in this paper. Most of the selected groups are junior colleges and colleges and above. The respondents have certain basic knowledge of project management and can fill in the questionnaires more professionally. In order to truly obtain the actual situation of the project, the questionnaires are mainly used. Select managers who have been working in project management positions for more than two years, which are more concerned with quality management activities and corporate performance related activities. 


\subsection{Basic Assumptions}

Research Hypothesis

This paper proposes the following assumptions:

H1 cost management is positively correlated with project profitability

The leadership role of H1-1 is positively correlated with project profitability.

H1-2 cost strategy is positively correlated with project profitability

H1-3 cost accounting analysis is positively correlated with project profitability

H1-4 cost control assessment is positively correlated with project profitability

$\mathrm{H} 2$ cost management is positively related to corporate growth

H2-1 leadership is positively correlated with long-term performance of the project

H2-2 cost strategy is positively correlated with project growth

H2-3 cost accounting analysis is positively correlated with project growth

H2-4 cost control assessment is positively correlated with corporate growth

$\mathrm{H} 3$ cost management is positively correlated with project performance

The leadership role of H3-1 is positively correlated with the overall performance of the project.

H3-2 cost strategy is positively correlated with project performance

H3-3 cost accounting analysis is positively correlated with project performance

H3-4 cost control assessment is positively correlated with project performance

\section{Empirical Data Analysis and Hypothesis Verification}

\subsection{Analysis of the Validity of the Questionnaire}

The fairness of the results of the questionnaire analysis depends not only on the appropriate sample area, sample size, accurate data statistics and scientific data statistics methods, but also on the validity and rationality of the questionnaire design(Xin Lu, Junyong Wu, Hui Huang,2014). Before getting this data and doing data analysis, it is necessary to analyze the effectiveness of the enterprise's quality cost and the six quantities of enterprise performance, that is, to carry out reliability analysis and validity analysis to verify the consistency within the scale and whether the questionnaire is valid.

\subsubsection{Reliability Analysis}

Reliability refers to reliability, which refers to the degree of consistency of the results obtained by repeating measurements on the same object in the same way, that is, the degree of accuracy of the test tool. In the actual analysis, test tools such as scales often use Alpha coefficients to analyze the reliability. It is the most commonly used data at present, which indicates the consistency between the scores of each item in the scale. This method is applicable to multiple scores of the project. The test data is either the data of the questionnaire. When the coefficient is lower than 0.35 , it is a low-signal meter, which should not be used. An acceptable scale is between 0.35 and 0.7 , and a coefficient higher than 0.7 is a high-signal scale.

After the questionnaire was retrieved, the reliability of the questionnaire was analyzed, and the coefficient of Alpha of each index was above 0.7. It can be seen that the scale has high internal consistency and good reliability, so the reliability is strong. .

\subsubsection{Validity Analysis}

Validity refers to effectiveness. It refers to the degree to which a measurement tool or means can accurately measure the things that need to be measured.Often, the validity analysis of a 
questionnaire includes content validity analysis and structural validity analysis. Content validity refers to the logic of the content of the questionnaire. Structural validity refers to the degree to which the results of the questionnaire can be explained by relevant theoretical evidence.If the structure produced can conform to the original structure, it has good structural validity, which means that the concept to be measured by the questionnaire has scientific significance and conforms to the theory. The idea above. Generally speaking, according to the relevant theoretical background, the structure of this paper is based on the definition and classification of cost management, the evaluation dimension theory of project performance is combined according to the design, and the relevant excellent questionnaires are also referred to in the design process. Finally, the comprehensive theory and actual situation the questionnaire for this study was designed, so this questionnaire is highly effective.

\subsection{Hypothesis Verification}

In view of the impact of project cost management on project performance, the research hypothesis is put forward. This paper mainly uses correlation analysis and regression analysis to verify the hypothesis, the regression coefficient equation between independent variable and dependent variable and the regression equation between independent variable and project performance. The specific hypothesis that can be derived is verified: First, the impact of the components of project cost management on the profitability of the project is different, and the assumption is basically verified. Second, the various components of cost management have a positive impact on the growth of the company, but the impact of each component on the growth of the company is different, and all assumptions are verified. Third, the various components of cost management have a positive impact on project performance. However, the impact of each component on its project performance is different, and all assumptions are verified. Through empirical analysis, this paper concludes that there is a positive correlation between cost management and project performance.

This paper verifies the analysis of the mechanism of the impact of cost management on project performance.

\subsection{Research Conclusions}

This paper sorts out the dimension indicators of cost management through literature review, draws on the measurement indicators used by the predecessors on project performance, and collects data through questionnaires. After empirical analysis, the following main conclusions are drawn:

(1) There is a significant correlation between cost management and component and project performance. The various components of cost management have different influence directions and degrees on profitability, and have positive impact on project growth and performance, but the degree of influence is different.

(2) Most of the impact of cost management components on project performance has greater impact on project growth than profitability.

\section{Problems in Project Cost Management and Suggestions for Improvement}

\subsection{Problems in Project Cost Management}

The following problems mainly exist in the project implementation process:

The emphasis on cost management is not enough, the cost awareness is not high, and the cost management is not comprehensive. 
Cost accounting is not in place. Many projects in the cost accounting process, the cost accounting method is relatively simple, the collection of cost accounting is not comprehensive, and the phenomenon of recording cost data casually exists in many projects.

Supervision is not in place. "Long-term cost control" is a common problem in project cost management

The lack of project cost control and management professionals can not effectively improve the overall cost control and management awareness of the project, resulting in difficult project cost control and management.

\subsection{Project Cost Management Improvement Suggestions}

\subsubsection{Improve the System of Project Cost Management}

It is necessary to change the inherent idea of developing local cost management, starting from the whole, and dynamically reviewing the development stage of the project, thereby forming cost and performance management. According to the characteristics of specific projects, the internal and external conditions, the constraints of resources and environment, and the screening of specific cost management paths

\subsubsection{Decomposition Performance Indicators}

The project participants should refine the cost management performance indicators on the premise of multiple discussions, and make optimized design for specific refinement content. On this basis, the project cost control indicators are formed through measurement.

\subsubsection{Establish a Sound Talent Training and Introduction Mechanism}

It is necessary to continuously improve the construction of relevant institutions engaged in project cost control, cultivate talents engaged in related work, and motivate relevant talents to increase their participation in project cost control. You can try to set up special funds for talent training, and help regular practitioners to unify theory and practice with regular vocational training.

\subsubsection{Establish Supervision and Evaluation Mechanism}

After completing the project cost planning, it is necessary to sign performance responsibility books with the respective indicators, create a sound supervision and evaluation system, implement the evaluation measures of rewards and punishments, implement the responsibility to individuals, form supervision and management for each process, and request temporary sites. The specific schemes are continuously optimized reasonably to ensure cost control within the specified range, reduce material consumption, minimize cost expenditure, ensure that the effectiveness of cost control is fully demonstrated, and achieve the goal of optimal project performance.

\section{Research Limitations and Prospects}

\subsection{Limitations of the Study}

Although this paper collects a large amount of literature, but because of the relatively low literature on the relationship between cost management and project performance, and the limited personal ability, some of the viewpoints in this paper will inevitably have certain defects, and the research process and structure will inevitably be insufficient. Where: 1 is limited to the professional nature, this article only studies the engineering construction projects, and does not distinguish 
between different development stages of the construction project. 2 sample data aspects. Although a large amount of data is collected in this paper, the data collection projects are mostly developed. The regression analysis based on the questionnaire is only the result of the questionnaire, and may not be general. At the same time, in the questionnaire survey, the questionnaire is inevitably with its own subjective color, which inevitably affects the objectivity and accuracy of the research results.

\subsection{Outlook}

Project cost management has a major impact on project performance. Understanding the relationship between project cost management and project performance, determining scientific management methods, and continuously improving the level of cost management are important means to improve project competitiveness. The development of project cost management is not mature enough, and there is still much to be done to explore the impact of project cost management on project performance.

\section{References}

[1] Binqing Ma, 2013.Discussion on the principles and methods of enterprise cost management [J]. Modernization of shopping malls, 13: 98

[2] Jifeng Zhang, 2017.Discussion on Performance Management in Project Cost Management [J].Building Technology Development, 44(15):51-52.

[3] Liang Liu, 2018. Environmental Regulation and Enterprise Performance from the Perspective of Long-Term Cost-Revenue [J].seeking,(04):103-109.

[4] Rui Yang, 2012. Research on the relationship between cost and corporate performance [D]. Donghua University.

[5] Wenlong Liu, Shiyou Hui, Xixue Xue, 2014. Research on the impact of asset-liability ratio and financial cost of construction engineering enterprises on performance [J].Engineering Economics,(03):3-9.

[6] Wenwu Ma, 2013.Research on Enterprise Cost Management [J]. China Foreign Capital, (09): 49+51.

[7] Xiaoli Duan, 2018.Research on Cost Management and Performance Audit of Modern Enterprises [J]. Journal of North China University of Hydraulic Engineering (Social Science Edition), 34(04): 37-40.

[8] Xin Lu, Junyong Wu, Hui Huang,2014.The Trend of Chinese Enterprises Cost Management—An Empirical Analysis Based on Literature Data[J].Journal of Industrial Engineering and Engineering Management,02:8-16.

[9] Yao Ge, 2017.The Impact of Cost Stickiness on Firm Performance_Evidence from Chinese Listed Companies [J]. Price Theory and Practice, (06): 105-109. 